\title{
Correction To: Evaluation of mechanical and adhesion properties of glass ionomer cement incorporating nano-sized hydroxyapatite particles
}

\author{
Mohit Kheur $^{1} \cdot$ Nidhi Kantharia $^{2} \cdot$ Tabrez Lakha $^{1} \cdot$ Supriya Kheur ${ }^{3} \cdot$ Nadin Al-Haj Husain $^{4} \cdot$ Mutlu Özcan $^{5}$
}

Published online: 4 June 2019

๑) The Society of The Nippon Dental University 2019

\section{Correction to: Odontology \\ https://doi.org/10.1007/s10266-019-00427-5}

In the original publication of the article, the family name of the author "Tabrez Lakha" was published incorrectly as "Tabrez lakha" and corrected in this publication.

In addition, the family name of the author "Nadin AlHaj Husain" is "Al-Haj Husain" not "Husain".

Publisher's Note Springer Nature remains neutral with regard to jurisdictional claims in published maps and institutional affiliations

The original article can be found online at https://doi.org/10.1007/ s10266-019-00427-5.

Mutlu Özcan

mutluozcan@hotmail.com

1 Department of Prosthodontics, M.A. Rangoonwala Dental College, Pune, Maharashtra, India

2 Department of Prosthodontics, College of Dental Sciences and Research Centre, Bopal, Ahmedabad, Gujarat, India

3 Department of Oral Pathology and Microbiology, D.Y. Patil Dental College, Pune, Maharashtra, India

4 Department of Reconstructive Dentistry and Gerodontology, School of Dental Medicine, University of Bern, Bern, Switzerland

5 Dental Materials Unit, Center for Dental and Oral Medicine Clinic for Fixed and Removable Prosthodontics and Dental Materials Science, University of Zürich, Plattenstrasse 11, 8032 Zurich, Switzerland 